\title{
Finite Element Analysis of Cold Formed Steel Purlin Bolted Connections
}

\author{
Kavya.E ${ }^{1}$, Swedha.T ${ }^{2}$ \\ ME Structural Engineering Student, Dept of Civil Engineering, Valliammai Engineering College, Chennai, India ${ }^{1}$ \\ Assistant Professor, Department of Civil Engineering, Valliammai Engineering College, Chennai, India ${ }^{2}$
}

\begin{abstract}
Cold formed steel sections are widely used as purlins in industrial buildings. Plain $\mathrm{C}, \mathrm{Z}$ and sigma sections are most common cold-formed steel purlins in use for roof systems throughout the world. In a pre engineered building of larger bay span two purlins are connected in such a way that it acts as a continuous member. The purlins are connected either by overlapping them or by bolting a short sleeve member that holds and connects the purlins. This paper aims in determining the capacities of bolted overlapped and sleeved connections for $\mathrm{z}$ and sigma section having same depth and thickness. The stability, load bearing capacity and failure modes for the four different connections are found by finite element. The finite element analysis is done by ABAQUS/CAE. Results are compared to find which connection case is more effective.
\end{abstract}

Keywords: cold formed steel, $\mathrm{Z}$ and sigma purlins, bolted connections, load carrying capacity.

\section{INTRODUCTION}

\section{GENERAL}

Cold-Form Steel buildings are a predetermined assembly of structural members that has proven over time to meet a wide range of structural and aesthetic requirements. Cold-Form Steel building concept originated during World War II in 1960's in the United States and made available in India in late 90's. These structures are assembled with only hand tools and with no greater effort could be readily dismantled and moved and re-erected somewhere else.

The scientific term Cold-Form Steel buildings came into being in the 1960's. The buildings were "Cold- Form Steel" because like their ancestors, they relied upon standard engineering designs for a limited number of off the shelf configurations. Cold-formed steel goods are created by the working of sheet steel using stamping, rolling, or presses to deform the sheet into a usable product.

\section{COLD FORMED PURLINS:}

In steel construction cold-formed structural members are becoming more popular and have a growing importance. Cold-formed steel exhibits a versatile nature which allows for the forming of almost any section geometry. Coldformed steel sections are usually thinner than hot-rolled sections and can be subject to different modes of failure and deformation and therefore extensive testing is required to provide a guideline for the design of cold-formed thinwalled structural members.

The main mechanical properties (yield point, tensile strength and ductility) of cold-formed steel sections, particularly at the corners, are considerably different from those of the flat steel sheet, plate, strip or bar before Forming. This is because the cold-forming operation increases the yield point and tensile strength, and at the same time decreases the ductility. Light gauge steel purlins are available in different cross sections. Most commonly used sections are C, Z, L and sigma section with or without lip.

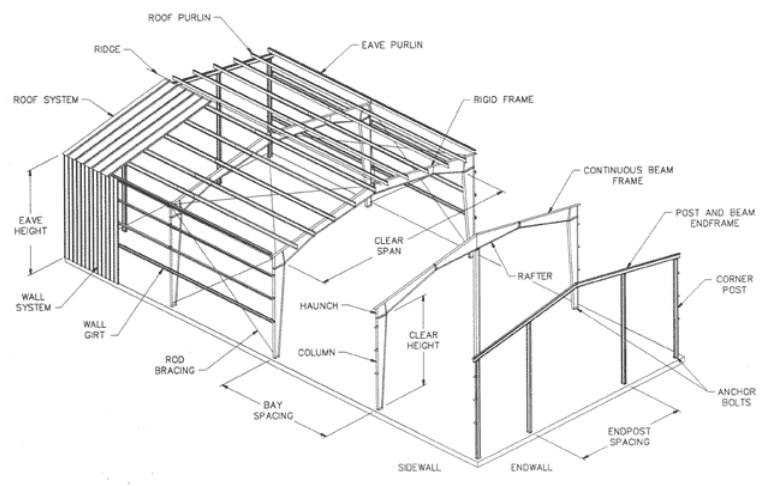

Fig 1.1 Components of industrial building 


\section{BOLTED CONNECTION}

The use of bolted connections is one of the most common methods for joining two lapped purlins at the supports. Conventional design practice assumes that the lapped bolted sections do not affect the continuity of the purlins. The strength and stiffness checking of the lapped connection is often performed by treating it as a homogeneous section and calculating the cross-sectional properties of the lapped sections to be double that of a single section. However, this assumption could lead to unsafe design because it neglects or oversimplifies the effects of the bolted connections. As a result, the behaviour and performance of these metal roof systems were not appropriately assessed. In the worst case, inadequate design of the purlin may directly lead to roof collapses. Types of failure mode in connections are (a) Longitudinal shear failure of sheet (type I). (b) Bearing failure f sheet (type II). (c) Tensile failure of sheet (type III). (d) Shear failure of bolt (type IV).

\section{SCOPE FOR THE STUDY:}

The scope this study is

$>$ Single, double and multi-span purlins could be connected in such a way that it acts as a continuous member throughout the building length.

$>$ Practical difficulty is reduced for erecting continuous purlins for large building length.

$>$ For a medium to large bay span industrial building, choice for selection of the effective section and connection type in purlins are found.

\section{OBJECTIVE:}

$>$ To analyze the capacity and typical failure modes of two different bolted connections (sleeved and overlapped).

$>$ To analyze the connections for the two sections by software and experimental results.

$>$ To compare the load bearing capacity of all the connection types for the same connection length.

$>$ To illustrate the Failure modes of connections.

\section{SUMMARY OF THE LITERATURE}

The capacity and section behaviour of cold formed steel are studied with help of literatures different points had been taken for the project

$>$ The ultimate eccentric loads are sensitive to the yield stress of the steel. The stability of Z-section members (under concentric loads) is sensitive to initial imperfections.

$>$ Sleeved purl in connections showed non-linear behaviour until failure.

$>$ A bolted connection in cold formed steel is such that complete rigidity is difficult to obtain.

$>$ The critical section of the sleeve connection may occur either in the purlin near the outer columns of bolts or in the sleeve near the centre of connection.

$>$ The corresponding failure modes are the local buckling in purlin webs due to a combined bending and local bearing action, tension fracture failure in the tension flange of sleeve due to the bending.

$>$ The elastic moment carrying capacity is directly proportional to the cross section of the member.

$>$ The characteristics of moment resistance and flexural stiffness in the slotted connections are dependent on the ratio of lap length to purlin depth, the ratio of lap length to purlin thickness, the ratio of purlin depth to purlin thickness, and the ratio of lap length to span.

\section{PURLIN SECTIONS AND CONNECTIONS}

The main process of cold formed steel structural elements involves forming steel sections in cold state sheets at uniform thickness. The thickness of steel member ranges from $0.4 \mathrm{~mm}$ to $6.4 \mathrm{~mm}$. The cold forming operation increases the yield point and ultimate strength of the steel sections.

\subsection{SECTION PROPERTIES}

Commonly used cold formed sections for purlin are $\mathrm{C}, \mathrm{Z}, \mathrm{L}$ and sigma section. In this study two purlin sections are chosen $\mathrm{Z}$ and sigma section.

\subsubsection{Z-SECTION}

A ' $Z$ ' section is a point symmetrical about a point (centroid). ' $Z$ ' sections having equal flanges are a point symmetric section. ' $Z$ ' section will buckle laterally at a lower stress than 'I' beam or channel section. . ' $Z$ ' section is taken code IS: 811-1987. Depth of section is taken as $200 \mathrm{~mm}$ and thickness of $2 \mathrm{~mm}$. properties of the section,

$\mathrm{h}=200 \mathrm{~mm}$

$\mathrm{b}=60 \mathrm{~mm}$

$\mathrm{c}=20 \mathrm{~mm}$

$\mathrm{t}=2 \mathrm{~mm}$

$\mathrm{I}_{\mathrm{xx}}=400 \mathrm{~cm}^{4}$ 
$\mathrm{I}_{\mathrm{yy}}=48.5 \mathrm{~cm}^{4}$

$\mathrm{Z}_{\mathrm{xx}}=8.22 \mathrm{~cm}^{3}$

$\mathrm{Z}_{\mathrm{yy}}=38.8 \mathrm{~cm}^{3}$
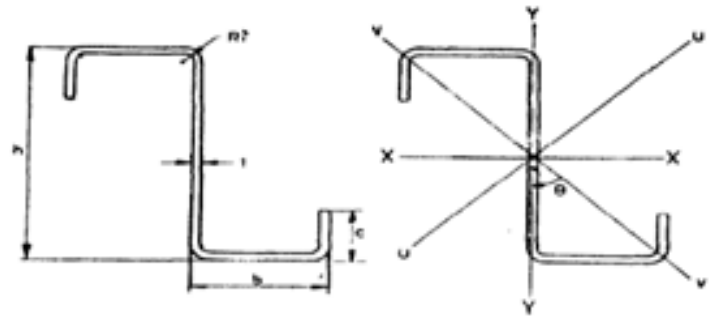

Fig 3.1: Z section as per IS:811-1987

\subsubsection{SIGMA SECTION}

Cold-formed steel sigma purlins normally possess advantageous structural features such as an enhanced web buckling resistance and a location of shear centre closer to the web. In comparison with their counterparts such as $\mathrm{Z}$ and $\mathrm{C}$ sections, sigma sections have an improved web buckling resistance due to the presence of web stiffeners. Lipped sigma section is taken for this study with respect to eurocode EN 1993-1-3-2006 with depth $200 \mathrm{~mm}$ and of thickness $2 \mathrm{~mm}$ .properties of the section,
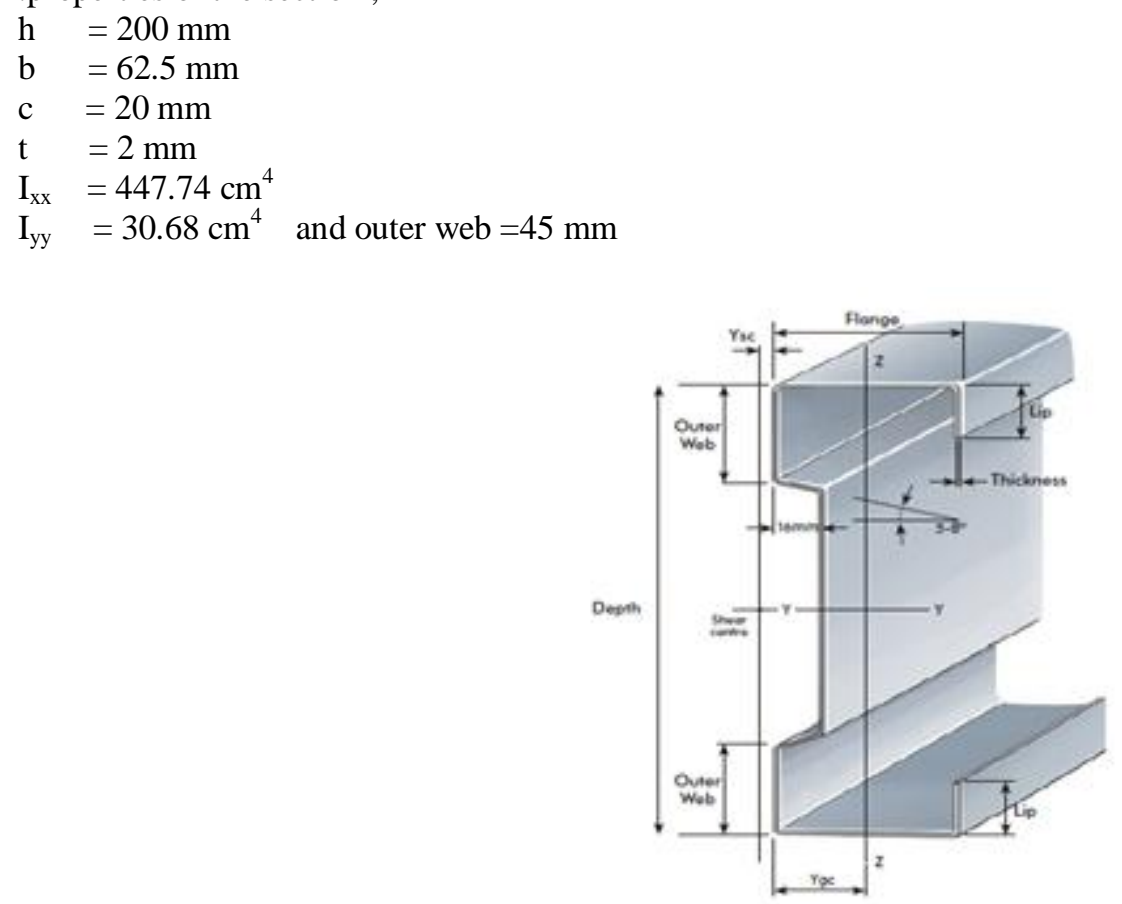

Fig 3.2: Sigma section based on Eurocode

\subsection{SELECTION OF CONNECTION}

Connections in steel are normally made either by bolting or welding. Bolting is common in field connections, since it is simple and economical to make. Bolting is also regarded as being more appropriate in field connections from considerations of safety. However, welded connections, which are easier to make and are more efficient, are usually resorted to in shop fabrications Purlins can be connected either by overlapping or connecting a small sleeve member and are bolted together. The size of bolt to be used here is $6 \mathrm{~mm}$ diameter the purlins can either be single span or double span purlin connection one or two bays of a pre engineered building respectively.

\subsubsection{OVERLAPPED CONNECTION}

In this type of connection purlins are provided with an extra length called overlapping length where it is lapped with adjacent purlin and are bolted together. Connections in this purlin are necessary as to provide continuity over entire length of the building. Lap length is distance between centre to centre of the edge bolts .lap length for a purlin connection depends on parameters like span of the beam, depth of the purlin section. The failure of an overlapped connection is directly proportional to the length ratio, which is the ratio of the lap length to beam span. In practice the normal lap length adopted is $12.5 \%$ of the bay span. 


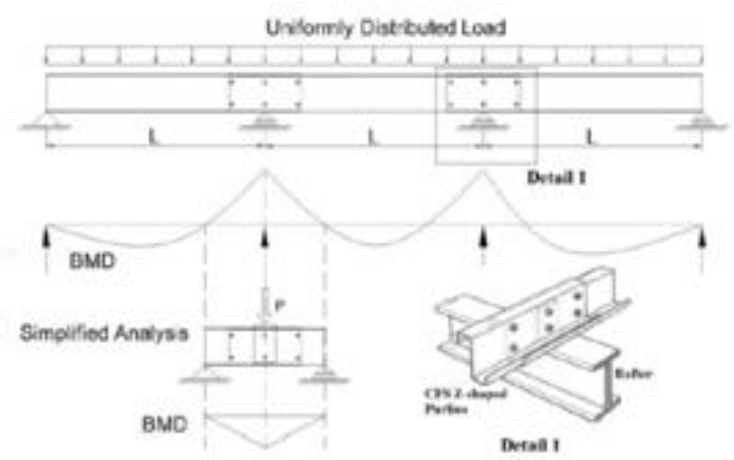

Fig 3.3: simplified analysis for lapped connection

In this project the span of the beam may be assumed as 4 meters and the lap length is 0.5 meters.

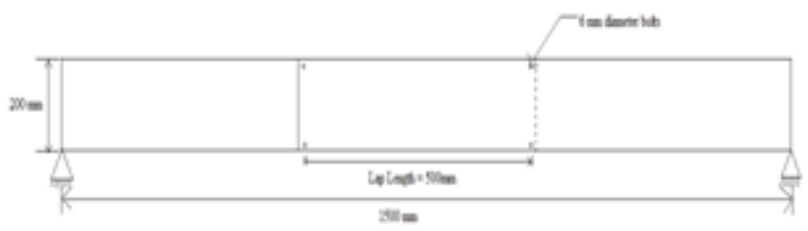

Fig 3.4 Schematic representation of lapped connection

\subsubsection{SLEEVED CONNECTION}

In this type of connection a short cold-formed steel member similar to the purlin that holds and connects both purlins. By careful design of sleeved connection it is possible to arrange that redistribution of moment occurs under load to produce equal maximum moments in the span and at the supports at failure. The sleeve length adopted here is $0.5 \mathrm{~m}$ as that for lapped connection for better analysis and comparison.

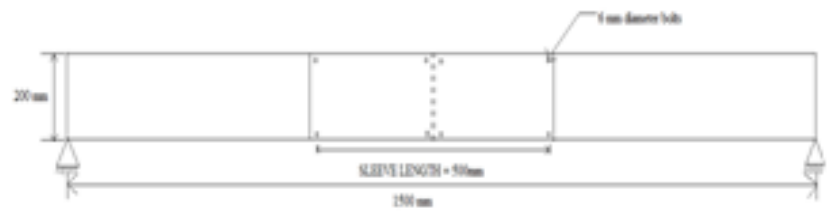

Fig 3.5: Schematic representation of sleeved connection

\subsection{CONNECTION CASES}

- Type 1 - Z section overlapped connection.

- Type 2 - Z section sleeved connection.

- Type 3 - sigma section overlapped connection.

- Type 4 - sigma section sleeved connection.

\section{FINITE ELEMENT ANALYSIS}

The finite element analysis for the four connection cases is done by ABAQUS/CAE software. Every complete finiteelement analysis consists of 3 separate stages:

- $\quad$ Pre-processing or modeling: This stage involves creating an input file which contains an engineer's design for a finite-element analyzer (also called "solver").

- $\quad$ Processing or finite element analysis: This stage produces an output visual file.

- $\quad$ Post-processing or generating report, image, animation, etc. from the output file: This stage is a visual rendering stage.

\subsection{MODELLING}

The first step in the model tree of abaqus/CAE is creating a model for which boundary conditions and loads are assigned for further analysis .It comes under the user action in abaqus where the user have to define the type of parts whether a shell or solid element, thickness of material and shape of the part . The total length of the specimen is $1.5 \mathrm{~m}$ and depth of both $\mathrm{Z}$ and sigma section is $200 \mathrm{~mm}$. 
ISO 3297:2007 Certified

Vol. 4, Issue 4, April 2017

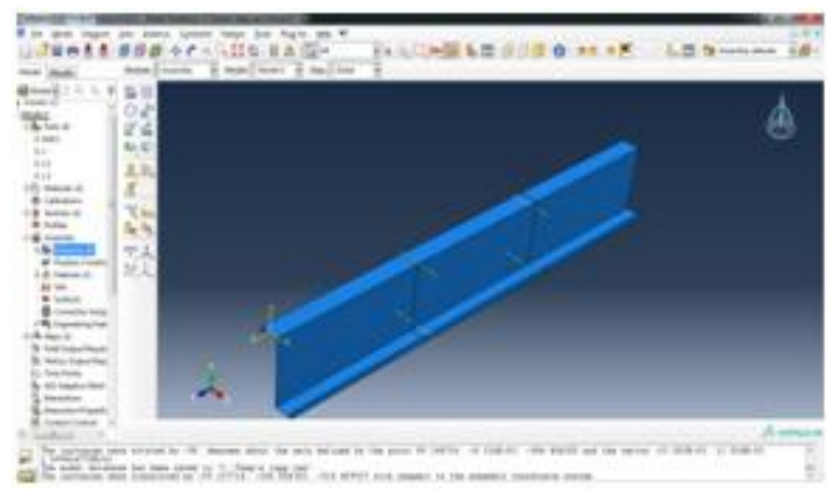

Fig 4.1: Model assembly for $\mathrm{z}$ section overlapped connection

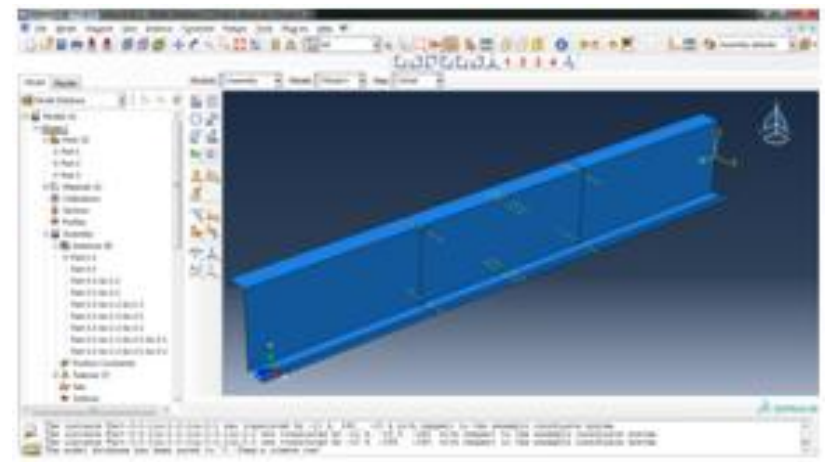

Fig 4.2: Model assembly for $\mathrm{z}$ section sleeved connection.

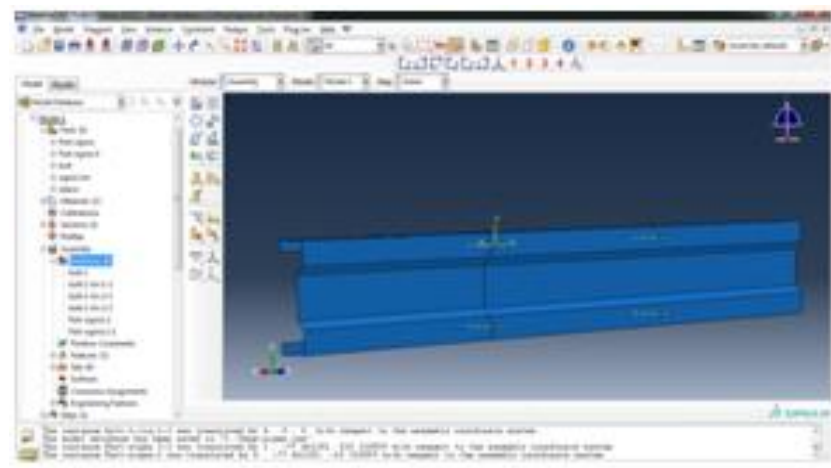

Fig 4.3: Model assembly for sigma section lapped connection.

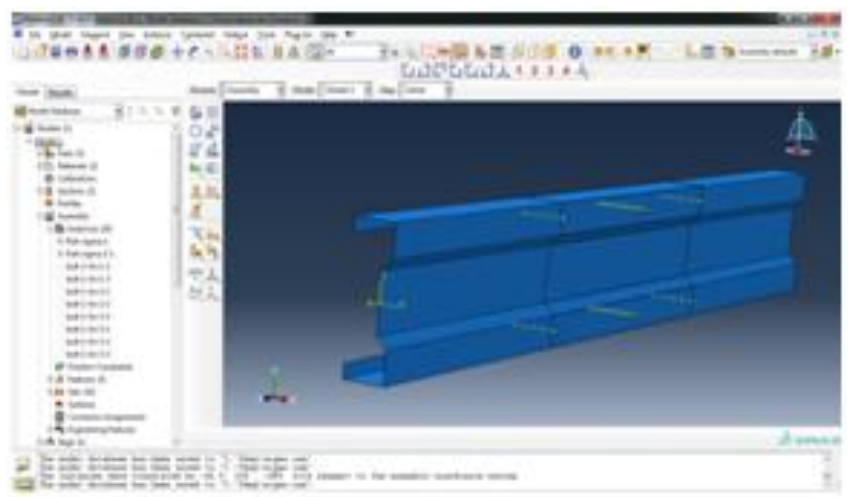

Fig 4.4: Model assembly for sigma section sleeved connection.

\subsection{MESHING AND ANALYSIS}

As per the simplified analysis mentioned in figure 3.3 a concentrated load is applied at the midpoint of the specimen with boundary conditions .the models are the meshed and analysis is done. 


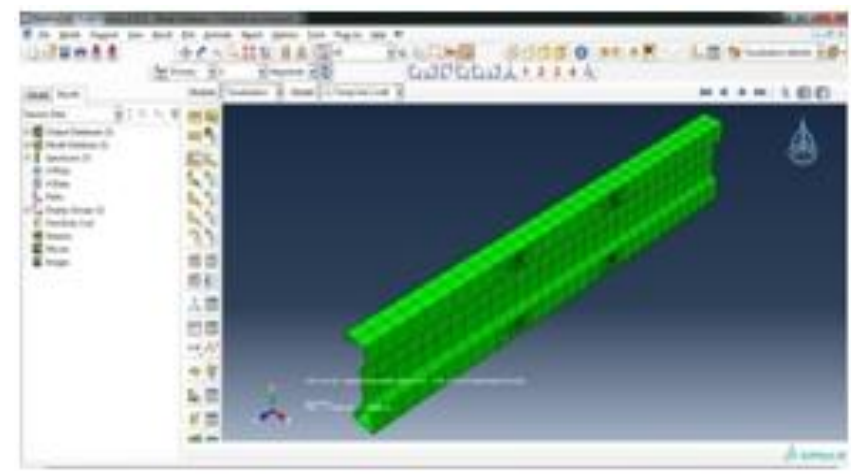

Fig 4.5: Meshing of the model (type 3)

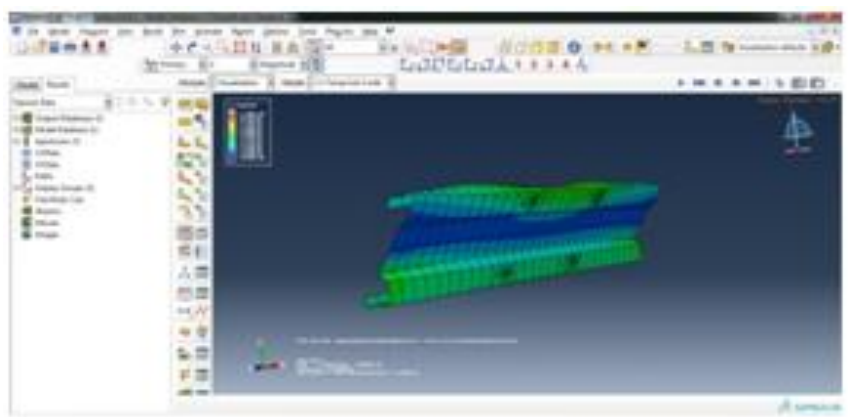

Fig 4.6: Buckling and stress distribution (type 3).

\subsection{RESULTS AND DISCUSSION}

From the analysis the ultimate load for all the connection cases and the failure modes are observed .Local buckling of flanges and web of purlin sections and distortional buckling of the sleeve section near edges are observed. The load carrying capacity of the four connection types is given in table below. Sigma section which is overlapped for the length $500 \mathrm{~mm}$ shows maximum capacity than other connections and is effective.

Table 1: ULTIMATE LOAD \& DEFLECTION FROM ANALYSIS

\begin{tabular}{|c|c|c|c|}
\hline TYPE & CONNECTION & PEAK LOAD (KN) & DEFLECTION AT MIDSPAN (mm) \\
\hline 1 & Z section overlapped & 17.89 & 7.25 \\
\hline 2 & Z section sleeved & 15.21 & 4.10 \\
\hline 3 & Sigma overlapped & 24.11 & 9.95 \\
\hline 4 & Sigma sleeved & 19.75 & 4.38 \\
\hline
\end{tabular}

\section{FAILURE PATTERN}

The connections $\mathrm{Z}$ section overlapped and sleeved (type $1 \&$ type 2 ) fails due to distortional buckling. Whereas the sigma section overlapped and sleeved connection (type $3 \&$ type 4) showed flexure-torsional buckling. Local buckling of purlin flanges and sleeve member occurred. The flexure torsional buckling occurred due to section asymmetry and location of shear centre of sigma section out of inner web.

Table 2: FAILURE MODES OF ALL CONNECTION CASES

\begin{tabular}{|c|c|c|}
\hline TYPE & CONNECTION & FAILURE PATTERN \\
\hline 1 & Z section overlapped & Distortional buckling \\
\hline 2 & Z section sleeved & Distortional buckling \\
\hline 3 & Sigma overlapped & Flexure-torsional buckling \\
\hline 4 & Sigma sleeved & Flexure-torsional buckling \\
\hline
\end{tabular}

\section{CONCLUSION}

The studies indicate that lap length is an important factor on determining the failure mode and for longer overlap the limit state was distortional buckling and sleeved connection shows lower strength and stiffness than lapped purlin For 
the purpose of analysis the lap length and sleeve length with arrangement and positions of bolts are also presented .The load bearing capacity of type 3(sigma section sleeved) connection is maximum of all other connections showing flexible behaviour of deflection about $9.95 \mathrm{~mm}$ at the ultimate load $24.11 \mathrm{KN}$. Further these sections are experimentally to be studies for their capacities and behaviour.

\section{REFERENCES}

[1] CODE OF PRACTICE FOR USE OF COLD-FORMED LIGHT GAUGE STEEL STRUCTURAL MEMBERS IN GENERAL BUILDING CONSTRUCTION ( IS: 801-1975).

[2] SPECIFICATION FOR LIGHT GAUGE STRUCTURAL STEEL SCTIONS (IS : 811-1987).

[3] “COLD FORMED STEEL SECTIONS" by Wei-Wen Yu, Ph.D., P.E.Curators' Professor Emeritus of Civil Engineering Director, Center for Cold-Formed Steel Structures University of Missouri-Rolla

[4] "PURLIN AND GRITS DESIGN GUIDE" by Stratco steel in accordance with limit state design principles and comply with the Australian/ New Zealand Standard AS/NZS 4600:2005 Cold-formed.

[5] Building Design Using Cold Formed Steel Section

[6] Mr. Roshan S Satpute, Dr. Valsson Varghese M.Tech (Structural Engineering) Karmaveer Dadasaheb Kannamwar College of Engineering.

[7] BSI Design of steel structures-cold formed structures. BS EN 1993-1-3:2006

[8] Rene W. Purnadi, John L. Tassoulas, Dimos Polyzoi (1990), “ A study of cold-formed z-section steel members under axial loading”, (October 23, 1990).International Specialty Conference on Cold-Formed Steel Structures. Paper 7

[9] D. B. Moore (1990), "Moment-rotation characteristics of purlin connections" (October 23, 1990). International Specialty Conference on ColdFormed Steel Structures. Paper 2.

[10] F. Zadanfarrokh , E.R.Bryan (1992), "Testing and design of bolted connections in cold formed steel sections" International Specialty Conference on Cold-Formed Steel Structures. Paper 3.

[11] Markku Laine, Pentti Makelainen (1994), "Study on the load-bearing capacity of cold-formed sigma purlins" (October 18, 1994).International Specialty Conference on Cold-Formed Steel Structures. Paper 2.

[12] Roge A.LaBoube, Wei-wen Yu, Michael L. Jones (1998), "Spacing of Connections in Compression Flanges of Built-up Cold-formed Steel Beams" (October 15, 1998). International Specialty Conference on Cold-Formed Steel Structures. Paper 4.

[13] Jian Yang, Qiang Liu (2011), "Sleeve connections of cold-formed steel sigma purlins" Int. Journal of Applied Sciences and Engineering Research, Vol. 1, Issue 3, 2012

[14] Sunil M.Hardwani, A.V.Patil (2012), "Study, test and designing of cold formed section as per AISI code" Int. Journal of Applied Sciences and Engineering Research, Vol. 1, Issue 3, 2012

[15] Govindasamy. P, Sreevidya .V, Dr.L.S.Jayagopal (2013), "Comparative Study on Cold Form Purlins for Distortional Buckling Behaviour" international journal of engineering sciences \& research technology.

[16] Anbuchezian .a, Dr. baskar.G(2013), "experimental study on cold formed steel purlin sections" IRACST - Engineering Science and Technology: An International Journal (ESTIJ), ISSN: 2250-3498,Vol.3, No.2, April 2013.

[17] Jingnan Liu (2014), "Structural Behaviour of Lapped Cold-Formed Steel Z-Shaped Purlin Connections with Vertical Slotted Holes" Int. Journal of Applied Sciences and Engineering Research, Vol. 1, Issue 3, 2012. 